\title{
Need for an Antipsychotic in a Case of Infective Insanity Between Siblings - A Therapeutic Approach
}

\author{
Email address: \\ sivabalanela@gmail.com (S. Elangovan) \\ ${ }^{*}$ Corresponding author
}

Vimalanathane Panneerselvam, Sivabalan Elangovan*

Department of Psychiatry, SRM Medical College \& Research Centre, Tamilnadu, India

\section{To cite this article:}

Vimalanathane Panneerselvam, Sivabalan Elangovan. Need for an Antipsychotic in a Case of Infective Insanity Between Siblings - A Therapeutic Approach. International Journal of Psychological and Brain Sciences. Vol. 3, No. 2, 2018, pp. 18-21. doi: $10.11648 / j . i j p b s .20180302 .11$

Received: May 25, 2018; Accepted: June 8, 2018; Published: July 5, 2018

\begin{abstract}
BACKGROUND: Shared Delusional Disorder is not uncommon and has been included in formal diagnostic classification systems. However, it is not frequently diagnosed. This is a case of a 21 year old female, unmarried, who presented to our OPD with prominent psychotic symptoms, particularly a fixed belief that she was being followed by someone for the last six years. Her elder sister, who was close to her emotionally also developed persecutory delusion of similar content within one year of its onset in the younger sister. Thus when they first presented to the OPD, both sisters had similar type of psychotic presentation. After separation of both sisters, psychotic symptoms improved in elder sister within one month. CONCLUSION: Shared Delusional disorder is not uncommon. The risk of induced delusion is more among those who have high emotional bonding and it disappears following separation of each other. So it is necessary to evaluate the family member of individuals suffering from psychiatric disorder to rule out Induced delusional disorders. The conceptual issues of the problem are also discussed.
\end{abstract}

Keywords: Shared Delusion, Induced Delusion, Induced Psychosis, Infective Insanity, Folie à Deux, Antipsychotics

\section{Introduction}

\subsection{Historical Perspectives}

Shared psychotic disorder (SPD) or folie a` deux, induced psychosis, and induced delusional disorder (IDD) is that which is shared by two or more people with close emotional links. The essence of this phenomenon is a transfer of delusions from one person (inducer) to another (recipient, involved or induced partner). Although the term folie à deux was first coined by Lasègue and Falret [1] in 1877, as has been described often in the literature, equivalent phenomena to this term had been previously alluded to by other French psychiatrists. In 1860, Baillarger called it "folie communiquée" (communicated psychosis) [2].

Legrand du Saulle [3] reported "idée de persecution communiquée ou délire à deux et à trois personnes" (communicated persecutory idea or delusion at two and three persons) in 1871 . He indicated that the psychiatric contagion of delusions from one person to another is possible under certain conditions (eg, one who is apparently more powerful, intelligent, and active than another becomes the inducer). Finally, Lasègue and Falret [1] published a long paper called "la folie à deux ou folie communiquée," which includes vivid and detailed descriptions of clinical cases and clearly detailed conditions that enable psychiatric contagion.

Régis [4] called a type of shared psychosis, in which there is no communication but there is simultaneity, "folie simultanée." In German-speaking psychiatry, FAD was traditionally called "induziertes irresein," which was coined by Lehman [5] and Scharfetter [6] and literally means "induced psychosis." In 1942, Gralnick [7] published a seminal review, "folie à deux - the psychosis of association." He presented a concise and effective definition of FAD as "a psychiatric entity characterized by the transference of delusional ideas and/or abnormal behaviour from one person to one or more others who have been in close association with the primarily affected patient.

In 1980, DSM III defined FAD as "Shared Paranoid Disorder" in which there is a persecutory delusional system 
that develops as a result of a close relationship with a person who already has an established paranoid psychosis. DSM III$\mathrm{R}$ [8] renamed shared paranoid disorder as "Induced Psychotic Disorder" and added a new criterion which required that the recipient did not have a psychotic disorder immediately prior to the induced delusion. In DSM IV [9], "induced psychotic disorder" (DSM III-R) was renamed again as "Shared Psychotic Disorder" and included stricter exclusion criteria against other psychotic disorders or mood disorders. In DSM V [10], this disorder is referred to as "Delusional symptoms in Partner of individual with Delusional Disorder".

As for ICD, the 10th edition [11] defined FAD as "induced delusional disorder." ICD does not contain very strict exclusion criteria for psychotic comorbidity but emphasizes the traditional theory of the condition for induction - that the delusion is induced from active inducer to passive recipient. Various terms, such as "inducer-induced," "principalassociate," or "primary-secondary," have been used to distinguish the partners in FAD.

Given the lack of literature and a well-defined set of symptoms it is hard to detect the clinical limits of FAD. Furthermore, the complex of comorbidities could lead to a misdiagnosis [18].

\subsection{Diagnosis}

\subsubsection{DSM IV - TR Diagnostic Criteria for 297.3 Shared Psychotic Disorder [12]}

A. A delusion develops in an individual in the context of a close relationship with another person (s), who has an already-established delusion.

B. The delusion is similar in content to that of the person who already has the established delusion.

C. The disturbance is not better accounted for by another psychotic disorder (e.g., Schizophrenia) or a mood disorder with psychotic features and is not due to the direct physiological effects of a substance (e.g., A drug of abuse, a medication) or a general medical condition.

\subsubsection{ICD 10 - F24 Induced Delusional Disorder [11]}

a) Two or more people share the same delusion or delusional system and support one another in this belief;

b) They have an unusually close relationship of the kind described above;

c) There is temporal or other contextual evidence that the delusion was induced in the passive member (s) of the pair or group by contact with the active member.

Includes:

* folie a deux

* induced paranoid or psychotic disorder

* symbiotic psychosis

Excludes:

* folie simultanee

\section{Case Report}

Two sisters, presented here as elder sister Ms. A and younger sister Ms. B, were brought to our OPD by their father on January 2017. They were both unmarried and belonged to a middle class nuclear family. According to their father, younger sister Ms. B was more sociable than Ms. A. There was a history of psychosis in their mother and maternal grandmother.

Ms. B pursued her undergraduate degree in English and lived along with Ms. A. Six years ago, she had developed behavioural disturbances in the form of irritability, being verbally abusive, exhibiting anger outbursts, decreased sleep and generalized body pain for which family members brought her to the Psychiatry OPD. At the time of assessment, she had referential and persecutory delusions. Also she had fleeting auditory hallucinations. She was diagnosed with paranoid schizophrenia and treated with $\mathrm{T}$. Risperidone.

Within one year of onset of illness in Ms. B, Ms. A, elder sister of Ms. B, also started exhibiting similar behaviour such as irritability and anger outbursts, decreased self-care and decreased sleep. She was diagnosed with hypothyroidism 2 years ago; she took treatment for 3 months and stopped. At the time of assessment, she also had referential and persecutory delusions and infrequent auditory hallucinations. The content of her delusions and hallucinations were similar to that of Ms B's. Furthermore, she became socially isolated and had poor interpersonal relationships. She was diagnosed with paranoid schizophrenia and treated with T. Risperidone.

For five years, they were on irregular treatment and the symptoms persisted. Whenever they consulted the psychiatrist in the intervening period, they came without the other although they were living together. In January 2017, their parents brought both the sisters to Psychiatry OPD and they were admitted for diagnostic workup and to ensure drug compliance. At the time of admission, we suspected the possibility of shared delusional content because of living in the same milieu with shared interactions.

We treated both the sisters with antipsychotics such as T. Risperidone in Ms. B whereas T. Amisulpride in Ms. A, while they stayed in separate rooms. Both the patients were discharged with partial improvement in symptomatology. At the time of discharge, parents were instructed to separate the sisters in order to see further improvement in their shared symptomatology. Both the sisters were prescribed antipsychotics and advised to follow up after one month. The younger sister stayed in her home whereas elder sister stayed in their aunt's home and advised to continue the same medications. On follow up, it was noticed that there was reduction in the severity of suspiciousness and threatening hallucinatory voices with the elder sister when compared with the younger sister.

\section{Discussion}

The importance of folie à deux becomes apparent when it is realised how few people in close association with deluded individuals actually do acquire delusions. A large number of patients with schizophrenia live in intimate association with 
their relatives, yet no such sharing of delusions occurs. Therefore, when it does happen, there is a need to identify the special factors that operate in each individual's case. In this case report, we have two sisters who have similar educational background, living in the same house, with family history of psychiatric illness in grandmother and mother. Interestingly, the younger sister developed psychotic symptoms first, followed by elder sister. Initially both were treated on an individual basis with antipsychotics but there was no improvement in their symptoms because of irregular treatment and maybe because of genetic vulnerability. We treated both sisters with appropriate antipsychotic drugs and separated them for a certain period and observed them. We found there was a definite improvement of symptoms in elder sister following separation. They also fulfilled all the criteria for a folie à deux described by Dewhurst and Todd [13]: (i) definite evidence that the partners had been in intimate association; (ii) a high degree of commonality in the content of delusion, although the formal psychosis may differ; and (iii) unequivocal evidence that the partners share support, and accept each other's delusions. This relationship has also been described and explained in terms of learning theory, which postulates that the induced learns the abnormal behaviour from the more dominant, more driving inducer, and becomes psychotic and behaves psychotically. Since they were siblings, a common genetic pool predisposing to a similar illness also has to be considered. It is also firmly suggested that organicity could be involved in the pathophysiology of psychotic disorder as evinced in multiple case reports that have shown Shared Psychotic Disorder associated with organicity. Recently a case report of coincidental mega cisterna magna with psychotic disorder, which implies possible neuroanatomical liability for shared psychotic disorder, has been reported [14]. Cases of Folie à deux involving patients with dementia are reported quite infrequently [19].

Psychodynamically, the submissive, induced person unconsciously acquires characteristics of the more dominant inducer. The dominant partner provokes the submissive one into accepting his/her delusions rather than risk the deterioration of a close and gratifying relationship. Folie à deux thus keeps the pair united, but increases their detachment from the world of reality [15]. One case report from China describes a 42-year-old patient who physically abused her father until he submitted to her delusions. Subsequently and for years, both sustained persecutory delusions against their neighbours. While the patient was undergoing treatment, the father continued reinforcing her delusions [20].

Identification is another psychological mechanism of paramount importance in the production of this condition. Deutsch took the matter still further, stating that 'close living together from the beginning is an expression of those unconscious forms which later bring both parties to a similar delusional idea; the common delusion appears to be an important part of an attempt to rescue the object through identification with it or its delusional system'. [15]

Dewhurst and Todd [13] suggested that in the psychosis of association, the dominant partner uses the powers of suggestion, which in its essentials resembles hypnosis, to convey his/her delusions to the weaker partner, although emphasizing that the essential dominance which is a prerequisite for this to occur arises from several and varied factors, such as superiority in age, intelligence, education and aggressive drive.

Critical review of literatures from 1942 to 1995 by Silveira et al., [16] findings revealed that

1. Males and females were affected with equal frequency.

2. There was equal prevalence in younger and older patients.

3. The majority of shared psychoses were equally distributed among married couples, siblings, and parent-child dyads.

4. Comorbid dementia, depression, and mental retardation were common.

5. Hallucinations were common

6. The majority of dyads were socially isolated, which further explains our case scenario.

\section{Conclusion}

Induced delusional disorder is not a new concept since it has been discussed in literature since the nineteenth century and various pioneers have conceptualized it. Commonalities in the reviewed literature include closed association, temporal relationship, similar phenomenon and disappearance of symptoms with separation. Poor prognostic factors include family history, and in the case of shared delusional disorder or infective insanity with the involvement of two siblings, the problems are refractory when they share the same environment. It is noted with the follow-up of this case that separation does play some role in improvement of the delusional content and threatening perceptual experiences. However, this has to be replicated in larger samples to conclude on this paradigm. Case reports by Kumar et al., [17] implied that the majority of patients with folie à deux require multiple treatments including separation, antipsychotics, individual and group psychotherapy, and family therapy.

\section{References}

[1] Lasègue $\mathrm{C}$, Falret $\mathrm{J}$ : La folie à deux ou folie communiqué [in French]. Ann Med Psychol 1877, 18:321-355.

[2] Fenning S, Fochtmann LJ, Bromet EJ: Delusional disorder and shared psychotic disorder. In Kaplan \& Sadock's Comprehensive Textbook of Psychiatry, vol 1. Edited by Sadock BJ, Sadock VA. New York: Lippincott Williams \& Wilkins; 2005:1525-1533.

[3] Legrand du Saulle H: Idées de Persécution Communiquées ou Délire à Deux et à Trois Personnes. Le Délire des Persécutions, Paris: Henri Plon; 1871.

[4] Régis E: La Folie à Deux ou Folie Simultannée Avec Observation Recueillies à la Clinique de Pathologie Mentale (Thèse). Paris: Baillière; 1880. 
[5] Lehman G: Zur casuistik des induzirten irreseins (Folie à deux). Arch Psychiatr 1883, 14:145-154.

[6] Scharfetter C: On the hereditary aspects of symbiotic psychoses. A contribution towards the understanding of the schizophrenia-like psychoses. Psychiatr Clin (Basel) 1970, 3:145-152.

[7] Gralnick A: Folie à deux-the psychosis of association. Psychiatr Q 1942, 16:230-236, 491-520.

[8] American Psychiatric Association: Diagnostic and Statistical Manual of Mental Disorders, edn 3. Washington, DC: American Psychiatric Association; 1980.

[9] American Psychiatric Association: Diagnostic and Statistical Manual of Mental Disorders, edn 4. Washington, DC: American Psychiatric Association; 1994.

[10] American Psychiatric Association: Diagnostic and Statistical Manual of Mental Disorders, edn 5. Washington, DC: American Psychiatric Association; 2013.

[11] World health organization: the ICD-10 classification of mental and behavioral disorders, edn 10. Geneva: world health organization; 1992.

[12] Psychiatry 2006; 5:11. American psychiatric association. Diagnostic and statistical manual of mental disorders. 4th ed. Text revised.

[13] Dewhurst K, Todd J. The psychosis of a association; folie à deux. J Nerv Ment Dis 1956; 124:451-9.
[14] Balcioglu YH, Kirlioglu SS, Berkol TD, Ozgen G. Coincidental mega cisterna magna with psychotic disorder: a possible neuroanatomical liability for a shared psychotic disorder; 2017.

[15] Enoch MD, Ball HN. Folie à deux. In: Enoch MD, Ball HN (eds). Uncommon psychiatric syndromes. 4th ed. New Delhi: Arnold Viva; 2004:179-208.

[16] Silveira JM, Seeman MV: Shared Psychotic disorder: A Critical Review of the Literature. Can J Psychiatry. 1995, 40: 389-395.

[17] Suresh Kumar P N, Subramanyam N, Thomas B, Abraham A, Kumar K. Folie à deux. Indian J Psychiatry 2005; 47:164-6.

[18] Delusional sharing: a history focus-on and case report of folie à deux. Balducci PM, Gobbicchi C, Moretti P, Tortorella A. Riv Psichiatr. 2017 Jul-Aug; 52 (4):168-171.

[19] A Contagious Disorder: Folie à Deux and Dementia. Cipriani G, Abdel-Gawad N, Danti S, Di Fiorino M. Am J Alzheimers Dis Other Demen. 2018 Jan 1:1533317518772060.

[20] Folie à deux by Proxy in a Father, after Physical Abuse by a Mentally Ill Daughter.

[21] Tay JL, Li Z. East Asian Arch Psychiatry. 2017 Sep; 27 (3):121-4. 